\title{
Awareness on safe grain storage practices among rural Women
}

\author{
SUDHA SONI* AND PRIYA VASHISHTHA \\ Department of Extension and Communication Management, College of Home Science, \\ C.S.A. University of Agriculture and Technology, KANPUR (U.P.) INDIA
}

\begin{abstract}
Women play an important role in sustaining and improving food security at global, national, community and household levels in various ways. Majority of women are involved in some agricultural activities and earning for their family among the foodgrains. Pulses are widely grown throughout the world and their dietary and economic importance is globally appreciated and recognized. The present study was conducted in Gonda district during 2012-2013. Multistage random sampling technique was adopted for the study. Total 80 respondents were selected from the village, Rasoolpur. The data were analyzed and tabulated statistically. Further, after studying the safe grain storage, it was found that 48.75 per cent women respondents were engaged to their family farms. Whereas 22.50 per cent women's were facing problems to lack of education.
\end{abstract}

KEY WoRDS : Storage practices, Awareness, Food grains

View Point Article : Soni, Sudha and Vashishtha, Priya (2014). Awareness on safe grain storage practices among rural women. Internat. J. Home. Sci. Extn. \& Comm. Mgmt., 1 (2): 115-118.

Article History : Received : 21.09.2013; Revised : 06.06.2014; Accepted : 18.06.2014 